\title{
Absolute Requirement of GDNF for Adult Catecholaminergic Neuron Survival
}

\author{
Alberto Pascual ${ }^{1,2,3}$, María Hidalgo-Figueroa ${ }^{1,3}$, José I. Piruat ${ }^{1,2}$, C. Oscar \\ Pintado $^{1}$, Raquel Gómez-Díaz ${ }^{1,2}$ and José López-Barneo ${ }^{1,2^{*}}$ \\ ${ }^{1}$ Instituto de Biomedicina de Sevilla, Hospital Universitario Virgen del Rocío/ \\ CSIC/Universidad de Sevilla. Sevilla, Spain. \\ ${ }^{2}$ Centro de Investigación Biomédica en Red sobre Enfermedades \\ Neurodegenerativas (CIBERNED), Spain \\ ${ }^{3}$ These authors contributed equally to this work.
}

* Correspondence:

Dr. José López-Barneo

Instituto de Biomedicina de Sevilla

Hospital Universitario Virgen del Rocío

Avenida Manuel Siurot s/n

41013-Sevilla

SPAIN

Phone: +34 955012648

Fax: +34 954617301

Email: Ibarneo@us.es 


\section{SUMMARY}

GDNF is a potent neurotrophic factor that protects catecholaminergic neurons from toxic damage and induces fiber outgrowth. However, the actual role of endogenous GDNF in the normal adult brain is unknown, despite GDNF-based therapies are considered promising for neurodegenerative disorders. We have generated a conditional GDNF-null mouse to suppress GDNF expression in adulthood, hence avoiding the developmental compensatory modifications masking its true physiologic action. After GDNF ablation animals showed a progressive hypokinesia and a selective decrease of brain tyrosine hydroxylase (TH) mRNA, accompanied of pronounced catecholaminergic cell death, affecting most notoriously the locus coeruleus (LC), which practically disappears, the substantia nigra (SN) and the ventral tegmental area (VTA). These data unequivocally demonstrate that GDNF is indispensable for adult catecholaminergic neuron survival, and also show that in physiologic conditions down-regulation of a single trophic factor can produce massive neuronal death.

Key words: endogenous GDNF, conditional gene deletion, neurodegeneration, dopaminergic cell death, noradrenergic neuronal death, Parkinson's disease, mouse model 


\section{INTRODUCTION}

In recent years, neurotrophic factors have emerged as promising therapeutic tools for neurodegenerative diseases due to their effects on the promotion of survival, differentiation and phenotype of neurons. Among these agents, the dopaminotrophic glial cell line-derived neurotrophic factor (GDNF) ${ }^{1}$, has raised special attention because of its possible usefulness in the treatment of Parkinson's disease $(P D)^{2}$. In rodent and primate models, GDNF has been shown to protect dopaminergic nigrostriatal neurons from neurotoxins and to induce fiber outgrowth when administered directly into the brain ${ }^{3-8}$. GDNF also preserves other neurons from neurotoxic damage; particularly noradrenergic cells in the locus coeruleus (LC), which are affected in early stages of PD as well as in Alzheimer's disease and other brain disorders ${ }^{9}$. The therapeutic effects of intrastriatal GDNF infusion on PD patients have been evaluated in two open-label clinical trials with encouraging clinical and neurochemical results ${ }^{10,11}$. However, a randomized, placebo-controlled trial performed on PD patients was halted due to safety concern ${ }^{12}$. GDNF-based therapies are still considered to be promising for PD and other neurodegenerative diseases ${ }^{13}$; although improvement of their effectiveness requires an understanding of the actual physiologic role of GDNF in the maintenance of catecholaminergic neurons in adult life, a fact that remains essentially unknown.

GDNF mRNA is found in several regions of the adult rodent brain ${ }^{9,14}$ and, within the peripheral nervous system, GDNF is highly concentrated in the adult carotid body $(\mathrm{CB})^{15,16}$, a dopaminergic organ used for autotransplantation studies in $\mathrm{PD}^{17-19}$. Research on genetically modified animal models in which the GDNF signalling pathway is disrupted have thus far failed to provide definitive 
information on the physiological neuroprotective action of GDNF in adult life. Homozygous GDNF knockout animals die during the early postnatal period due to agenesis of the kidneys and myenteric plexus. At birth, $G D N F^{--}$animals show normal numbers of catecholaminergic neurons in the substantia nigra (SN) and LC, thus suggesting that compensatory neuroprotective mechanisms may be activated during development ${ }^{20-22}$. Heterozygous $\left(G D N F^{+-}\right)$animals are fertile and develop normally, although they manifest an accelerated decline in spontaneous motor activity and coordination with age ${ }^{23}$. Nevertheless, this embryonic GDNF deficit seems to have little impact in the adult as, at twenty months of age, the animals show only a 15\% decrease of tyrosine hydroxylase (TH) positive SN neurons and no differences in striatal TH+ fiber density with respect to controls ${ }^{23} . G^{2} N^{+/-}$mice, however, appear to exhibit a higher susceptibility to neurotoxin-induced long-term degeneration of monoaminergic neurons than wild type littermates ${ }^{24}$. Region-specific genetic deletion (driven by the dopamine transporter promoter) of Ret, a component of the GDNF receptor complex, in dopaminergic neurons has provided conflicting results regarding the role of this pathway in maintenance of adult neurons. A comparative morphometric and biochemical analysis of dopaminergic nigrostriatal neurons in adult Ret-null mice versus controls showed no differences ${ }^{25}$. Another group has reported that embryonic deletion of Ret in catecholaminergic neurons resulted in a significant decrease of $\mathrm{TH}+\mathrm{SN}$ neurons and striatal nerve terminals at two years of age, although, surprisingly, neurons in the ventral tegmental area (VTA) and LC remained unaffected ${ }^{26}$.

Here, we report the successful generation of a conditional GDNF-null mouse in which GDNF expression was markedly reduced in adulthood, hence 
avoiding the establishment of developmental compensatory modifications masking the true physiologic action of GDNF in the adult nervous system. These animals show selective and extensive catecholaminergic neuronal death, most notably in the LC, SN and VTA. Gabaergic and cholinergic pathways appear to be unaffected. The neurochemical and histological alterations in GDNF-deprived animals induce the progressive appearance of behavioral motor disturbances. These data unequivocally indicate that endogenous GDNF is absolutely required for trophic maintenance of catecholaminergic neurons in normal adult rodents. 


\section{RESULTS}

\section{Neurochemical alterations in conditional GDNF KO mice}

Generation of the floxed GDNF allele $\left(G D N F^{\digamma}\right)$ is shown schematically in Fig. 1a. We designed a targeting construct containing the mouse GDNF exon 3 flanked by loxP sites and neomycin resistance markers. Embryonic stem (ES) cells were electroporated with this construct and homologous recombination with the wild type locus resulted in the targeted (floxed) allele GDNF ${ }^{F}$. Positive clones of ES cells were selected by neomycin resistance and analyzed by Southern blotting for proper integration of the floxed allele (Fig. 1a and $\mathbf{b}$ ). Routine genotyping of mice carrying the wild type and floxed alleles was done by PCR (Fig. 1a and c). GDNF $F^{F /+}$ animals were interbred with $G D N F^{+/-}$mice carrying the Cre-Esr1 transgene ${ }^{27}$. In the resulting GDNF ${ }^{F /-}$, Cre (cGDNF) offspring the ubiquitously expressed Cre recombinase was activated at two months of age by administration of tamoxifen (TMX) to switch off GDNF expression. The appearance of the GDNF-null allele in the germ line of TMtreated animals was experimentally tested (see Methods). Animals were sacrificed at one, three or seven months after TMX treatment for GDNF protein measurements (P), DNA and RNA analyses, and histological studies (H) (Fig. 1d). Confirmation for the excision of the floxed allele in adulthood was done by PCR of striatal DNA using specific probes (Fig. 1a and e). The proportion of wild type GDNF alleles that remained in striatal neurons after TMX treatment was estimated by qPCR to be $18 \%$ of that in control animals (relative values, $0.18 \pm 0.06, n=5 \mathrm{TMX}+$ mice versus $1 \pm 0.22, n=3 \mathrm{TMX}-$ mice; $p<0.05)$.

GDNF mRNA expression in the various mouse strains studied was evaluated by quantitative RT-PCR performed on whole brain extracts (Fig. 1f). 
Embryonic GDNF heterozygosity resulted in a mild, non-significant decrease of total brain GDNF mRNA that was similar in $G D N F^{+/-}$and $G D N F^{F /-}$ strains thus indicating that the floxed and wild type GDNF alleles were transcribed with similar efficiency. In these two embryonic heterozygous animals, however, GDNF mRNA was $75 \%$ the amount seen in the wild type mice thus indicating compensatory activation by the remaining half normal alleles. Administration of TMX had no effect on wild type animals, but in cGDNF mice it induced a marked $(\sim 60 \%$ with respect to $+/+$ animals; $p<0.01)$ reduction of GDNF mRNA (Fig. 1f). Besides these mRNA measurements we also estimated the concentration of GDNF protein in striatal homogenates, a region of the adult rodent brain with high GDNF expression level ${ }^{9,16}$, using a highly sensitive ELISA assay. In fair agreement with the mRNA data, TMX induced an $\sim 60 \%$ decrease of striatal GDNF content with respect to controls (Fig. 19). These results suggest that although TMX treatment of $c G D N F$ mice left only $\sim 18 \%$ of alleles unaffected, the animals were able to produce up to $\sim 40 \%$ of the normal amount of GDNF mRNA and protein. As explained above, this probably reflects compensatory transcriptional up-regulation of the functional GDNF allele in the embryonic $G D N F^{F /-}$ animals. GDNF depletion produced a selective decrease of brain TH mRNA content, leaving choline acetyltransferase (CHAT) and glutamic acid decarboxylase (GAD1) mRNA levels unaltered (Fig. 1h). The data demonstrated a substantial decrease of brain GDNF in the conditional GDNF knockout mouse and suggested the existence in these mice of catecholaminergic cell damage without affectation of cholinergic or gabaergic neurons. 


\section{Selective neuronal death in GDNF-depleted adult brain}

To evaluate the impact of TMX treatment and subsequent GDNF depletion on neuronal viability we performed stereological cell counts in brain regions, such as the SN, VTA and LC, containing catecholaminergic neurons whose vulnerability to neurotoxins is prevented by $\mathrm{GDNF}^{3,8,9,24}$. The most representative data obtained from these experiments are illustrated in Figs. 2 and 3 and a quantitative summary is given in Table 1. Embryonic GDNF heterozygous animals (GDNF $F^{F /}$ strain) showed no effect regarding the number of $\mathrm{TH}+$ neurons in the SN, VTA and LC compared with controls $\left(G D N F^{+/ F}\right.$ strain, Table 1). Deletion of the floxed GDNF allele with TMX gave rise, however, to a progressive reduction in the number of $\mathrm{TH}+$ cells in SN and VTA. On average, the decrease in $\mathrm{TH}+$ neurons was small and statistically non-significant at one month after $\mathrm{TH}$ treatment but was very pronounced $(\sim 60-70 \%$ of $\mathrm{TH}+$ cell reduction) at seven months after GDNF gene deletion (Fig. 2a-d and Table 1). In parallel with the reduction in $\mathrm{TH}+$ cell number we observed a clear and significant decrease in the total number of neurons both in the SN and VTA (Fig. 2e-h and Table 1). These observations indicated that the decrease of $\mathrm{TH}+$ cells in GDNF knockout animals does not simply reflect down-regulation of $\mathrm{TH}$ gene expression. The disappearance of mesencephalic $\mathrm{TH}+$ neurons was accompanied by diminishment of $\mathrm{TH}+$ striatal nerve terminal density, particularly in the ventral region (Table 1). Progressive neuronal death in GDNF-deprived animals was particularly dramatic in the LC since evidence of $\mathrm{TH}+$ neurons in this nucleus almost disappeared in cGDNF at seven months after TMX treatment and the total number of Nissl+ neurons in the nucleus decreased markedly (Fig. 3a-f and Table 1). The death of mesencephalic 
catecholaminergic neurons in GDNF-deprived animals was paralleled by a decrease of $\mathrm{TH}+$ cell numbers in structures of the peripheral nervous system, such as the carotid body (CB; Fig. $\mathbf{4 a , b}$ and Table 1) or the superior cervical ganglion (SCG; Table 1).

Neuronal loss observed in cGDNF mice was not general but restricted to the aforementioned brain areas. For example, the number of $\mathrm{TH}+$ cells in the arcuate nucleus (AN), a component of the hypothalamic dopaminergic system, was unchanged (Fig. 4c-e and Table 1) and no apparent gross histological alterations were observed in the hippocampus or in neocortical regions (Supplementary Fig. 1). TMX treatment did not elicit macroscopic anatomical modifications in gut or kidney in animals studied up to 8 months after TMX treatment. Similarly, we did not observe changes in weight of TMX-treated cGDNF mice, which was maintained unaltered during the first 3-4 months despite the ongoing neurodegenerative process (respectively, $22.3 \pm 1 \mathrm{~g}, n=3$ versus $22.6 \pm 0.4, n=4$ wild type and GDNF-depleted animals studied 134 days after TMX treatment). Although not studied in detail yet, animal weight did, however, appear to decrease in older (> 200 days after TMX treatment) GDNF knockout animals.

Given the striking dependence on GDNF of mesencephalic dopaminergic and noradrenergic neuronal survival, we searched for the location of putative targets constitutively expressing high levels of GDNF and therefore critical for the trophic maintenance of the cells. To this end we used the heterozygous GDNF ${ }^{\text {LacZ }}$ mice, a tool that allowed us to identify cells with high levels of GDNF expression by the characteristic blue X-gal staining ${ }^{16,22}$. After systematic analysis of the brain we consistently found X-gal+ deposits in cells distributed 
throughout the striatum, in the anteroventral (particularly the ventrolateral region) and anteromedial nuclei of the thalamus as well as in the septum (mainly in the mediolateral region) (Supplementary Fig. 2a-e). These structures are innervated by projections from catecholaminergic neurons of the SN, VTA and LC ${ }^{28,29}$. Surprisingly, a high level of GDNF expression was also observed in the subcommissural organ (SCO; Supplementary Fig. $\mathbf{2 f}$ and $\mathbf{g}$ ), an ependymal secretory gland located in the roof of the third ventricle that participates in cerebrospinal fluid homeostasis ${ }^{30}$.

\section{Behavioral motor abnormalities in GDNF-depleted mice}

To assess the motor performance of the conditional GDNF knockout mice, animals were subjected to open field tests ${ }^{31-34}$. We analyzed the horizontal and vertical locomotor activity, with estimation of the distance traveled and time spent walking, as well as the number and duration of rearings. These are wellestablished behavioral tests used to characterize animals with deficit in the dopaminergic nigrostriatal pathway ${ }^{31-34}$.

GDNF-depleted animals showed a clear hypokinetic syndrome, progressively aggravated with time after TMX treatment. In fair agreement with the histological data (see Figs. 2-4 and Table 1), open field impairments were mild during the first weeks after TMX treatment but became quite obvious after three to four months of GDNF deprivation (Fig. 5). Although the number of cases studied to date is still small, the data available strongly suggest that the motor deficits continue to progress as TMX treated $C G D N F$ animals get older. 


\section{DISCUSSION}

The results demonstrate that endogenous GDNF exerts an indispensable neurotrophic effect on catecholaminergic neurons of the adult mouse nervous system, particularly with respect to the ventral mesencephalic dopaminergic neurons in the SN and VTA as well as the noradrenergic cells in the LC. The dependence of neuronal survival on GDNF is observed despite, on average, the trophic factor is down-regulated to only $40 \%$ of its content in normal adult brain. It had previously been shown that intracerebral administration of exogenous GDNF can protect catecholaminergic neurons from toxic damage, and that striatal over-expression of GDNF induces sprouting of dopaminergic fibers ${ }^{3,4,6-9}$. It had also been reported that postnatal survival and phenotypic expression of ventral mesencephalic dopaminergic neurons in tissue explants is favored by $\mathrm{GDNF}^{35}$. However, the actual physiologic role of GDNF in preserving adult brain catecholaminergic cells in vivo has, until now, been unknown. Our results contrast with the practically absence of neuronal damage in GDNF heterozygous or in animals without canonical GDNF (Ret) receptors ${ }^{20,23,25,26}$. Hence, it seem highly likely that embryonic gene disruption of the GDNF signaling pathway induces developmental compensatory mechanisms involving other neurotrophic factors and/or GDNF receptors. The existence of Retindependent GDNF receptors in adult mammalian brain is well documented ${ }^{14,36}$ and, additionally, it has been shown that both in vitro and in vivo effects of GDNF on midbrain dopaminergic neurons can be antagonized with anti-NCAM function blocking antibodies ${ }^{37}$. Thus, our findings support the idea that GDNF receptors other than Ret could play a significant physiologic role in adult brain. 
The strict dependence of adult catecholaminergic neuronal survival on endogenous GDNF prompted us to search for brain areas with high GDNF expression levels. Using a genetic marker ${ }^{16,22}$, we have demonstrated that besides in the striatum, GDNF is highly expressed in the septum as well as in the anteroventral/anteromedial thalamus, preferential targets of projections from catecholaminergic neurons of the SN, VTA and $L^{28,29}$. These same brain areas had been shown before to express high GDNF mRNA levels using Northern analysis and in situ hybridization techniques ${ }^{9,14}$. Interestingly, we have also seen a previously unnoticed robust GDNF expression in the SCO, an enigmatic glial-derived secretory gland in the third ventricle that participates in cerebrospinal fluid homeostasis ${ }^{30,38}$. The actual physiologic role of GDNF in SCO cells is an open, and quite appealing, question that must be addressed in future experimental work.

The striking reliance of adult mammalian mesencephalic catecholaminergic neurons on the continuous supply of GDNF further supports its potential use as a therapeutic agent in Parkinson's disease (PD), and possibly other neuronal disorders ${ }^{2}$. In this regard, GDNF delivery to multiple targets (striatum, thalamus and septum) rather than solely to the striatum, mimicking the physiologic trophic activation of catecholaminergic cells, may improve the efficacy of current clinical protocols. On the other hand, the pattern of cell death induced by GDNF down-regulation in adult brain recapitulates many of the neuropathological hallmarks of PD. Besides progressive dopaminergic cell death in SN and VTA, this phenotype is particularly evident in the $L C$, a region known to contribute to the pathophysiology of PD that degenerates early in the progression of the disease ${ }^{9,39}$. Interestingly, 
dopaminergic neurons in the hypothalamic arcuate nucleus, unaffected in $\mathrm{PD}^{40}$, are also preserved in GDNF-null adult animals. In parallel with the histological modifications, GDNF-depleted animals progressively develop a hypokinetic phenotype, similar to that reported in mice with toxic damage of the nigrostriatal pathway and $\mathrm{LC}^{31-33,41}$, which is fully compatible with the behavioral changes seen in PD. Hence, the conditional GDNF knockout mice model should facilitate the understanding of neuroprotective pathways induced by GDNF, the study of PD pathogenesis, as well as the development of novel therapeutic tools to fight neurodegeneration.

\section{METHODS}

Generation of animal models. Animals were housed under temperaturecontrolled conditions $\left(22^{\circ} \mathrm{C}\right)$ in a $12 \mathrm{~h}$ light/dark cycle. All experiments were performed in accordance with institutional guidelines approved by the ethics committee of the "Hospital Universitario Virgen del Rocio". To generate the conditional GDNF animals, we engineered a targeting construct that could be homologously recombined into the third coding exon of the GDNF locus. The targeting construct contained GDNF exon3 (E3) flanked by loxP sites (GDNF ${ }^{F}$ ) and the neomycin resistance marker. For homologous recombination, we used 129Sv-derived R1 ES cells. Southern blotting using a DNA 3' probe was used to identify the recombined allele. $G D N F^{F}$ mice were further propagated and used for experiments on a mixed genetic background (129/SvJ:C57BL/6). Routine genotyping to detect the wild-type or floxed allele was performed using PCR. Floxed PCR was performed with the primers loxP15 (5'TCACGTGTCTATGTGCTAAA-3') and loxP13

AATGATCATTTCGGGCAGTC-3'). To obtain the experimental model used in this study, GDNF ${ }^{L a c z}$ animals $\left(G D N F^{+-}\right)^{22}$ were mated with Cre-Esr $1 /+^{27}$ mice to obtain a $\mathrm{F} 1 \mathrm{GDNF}^{+/}$; Cre/+ progeny. $\mathrm{F} 1$ animals were mated with $\mathrm{GDNF}^{\mathrm{F} /+}$ mice to generate control $\left(G D N F^{+/ F} ;+/+\right)$ and experimental littermates $\left(G D N F^{F /-}\right.$; Cre/ or cGDNF). Two-month-old animals were intraperitoneally injected with 
TMX (Sigma; $0.2 \mathrm{mg} / \mathrm{g} /$ day) for four consecutive days. TMX was prepared and used as previously described ${ }^{42}$. cGDNF mice without TMX treatment were used as control when indicated. To test for the successful conditional deletion of GDNF in vivo, excised PCR was used with the primers loxP15 and loxP23 (5'GAACTCCAGGTAAATAATCC-3'). To verify the effect of TMX and the proper excision at the $G D N F^{F}$ locus, GDNF $F^{+/ F}$; Cre-Esr1/+ mice treated with TMX were mated with wild-type animals. Heterozygous GDNF-null mice in the progeny were crossed and, as expected, the resulting offspring carrying the two excised alleles died during the first postnatal day due to renal agenesis.

DNA extraction from brain paraffin slices. Striatal paraffin-embedded slices $20 \mu \mathrm{m}$ thick were deparaffined twice with xylene and hydrated by washing with solutions containing decreasing concentrations of ethanol. Four slices were digested for 2 hours at $55^{\circ} \mathrm{C}$ in $200 \mu \mathrm{l}$ of directPCR reagent (Viagen) containing proteinase $\mathrm{K}(15 \mu \mathrm{g} / \mathrm{ml})$. Proteinase $\mathrm{K}$ was inactivated by heating samples at $85^{\circ} \mathrm{C}$ for 2 hours. $1 \mu \mathrm{l}$ from the resulting DNA solution was used for PCR analysis.

Quantitative RT-PCR. To determine GDNF, TH, Chat, and Gad1 mRNA levels, brain RNA was extracted using TRIzol reagent (Invitrogen) in a homogenizer (Omni 2000). RNA samples $(5 \mu \mathrm{g})$ were treated with DNase-RNase free (GE Healthcare) and copied to cDNA using SuperScriptll reverse transcriptase (Invitrogen) in a final volume of $20 \mu \mathrm{l}$. Real time PCR was performed in an ABI Prism 7500 Sequence Detection System (Applied-Biosystems) using SYBR Green PCR Master mix (Applied-Biosystems) and the thermocycler conditions recommended by the manufacturer. PCR reactions were performed in duplicates in a total volume of $25 \mu \mathrm{l}$ containing $1 \mu \mathrm{l}$ of the RT reaction. In each sample, Actb and Ppia RNA levels were estimated to normalize for RNA input amounts. Relative quantifications using both housekeeping genes produced similar results. To normalize mRNA levels in knockout mice to those in control samples, an average $\mathrm{Ct}$ of the control samples was calculated and all the samples in the experiment were processed relative to this average Ct. To estimate DNA recombination at the GDNF locus qPCR was performed on DNA 
samples extracted from striatal paraffin-embedded slices. The excision of the floxed allele was calculated estimating Neo gene dosage after TMX treatment. DNA amounts were normalized to beta glucuronidase (Gusb) levels. Primers used for qPCR appear online (Supplementary Methods).

GDNF ELISA. Striatal GDNF protein content was estimated using a commercial ELISA kit (GDNF Emax Immunoassay System; Promega, WI). Brain was removed and immediately frozen in liquid nitrogen. Left and right striata were dissected out, placed in $200 \mu \mathrm{l}$ of $20 \mathrm{mM}$ Tris- $\mathrm{HCl}, \mathrm{pH}=7.6,150 \mathrm{mM} \mathrm{NaCl}$, $0.05 \%(\mathrm{v} / \mathrm{V}) \mathrm{NP}-40$ and proteinase inhibitor cocktail (SIGMA), and sonicated with a Branson-150 sonifier for $10 \mathrm{~s}$ (output 2-3). Samples were centrifuged at $4^{\circ} \mathrm{C}$ for $10 \mathrm{~min}$ at maximal speed in a microcentrifuge and supernatant were removed and frozen. Protein concentration was performed with Bio-Rad protein quantification kit and $100 \mu \mathrm{g}$ of protein were used in the assay. ELISA was performed following the manufacturer's protocol. Neonatal (P1) protein extracts of forebrains from wild-type and $G D N F^{-}$animals were used as positive and negative controls. Absorbance from $G D N F^{-}$extracts was subtracted to each individual measurement. GDNF content was estimated in left and right striata and an average per animal was used to perform comparative analysis.

Tissue preparation and histochemistry. Animals were anesthetized and fixed with $4 \%$ paraformaldehyde. The brain and the carotid bifurcation were extracted and paraffin embedded. Coronal mouse brain sections (thickness $20 \mu \mathrm{m}$ ) were used for tyrosine hydroxylase (TH), NeuN-TH immunohistochemistry, or Nissl staining $(0.1 \%$ cresyl violet) in quantitative and morphometric studies. The Envision $^{+}$kit (DAKO) was used for immunohistochemistry according to the recommended manufacturer's protocol. Antibodies and the dilution factors used were as follows: anti-TH polyclonal antibody (Pel-Freez), 1:1000; anti-NeuN monoclonal antibody (Chemicon), 1:200. For double labeling with anti-TH and anti-NeuN antibodies we incubated the slices with antibodies against mouse antibodies and the signal was developed with DAB (DAKO). To increase contrast, a DAB enhancer (DAKO) was used. Antibodies against rabbit antibodies were added in a second step and the reaction developed with AEC 
substrate (DAKO). ß-galactosidase staining of $50 \mu \mathrm{m}$-thick brain slices was performed as described previously ${ }^{16,22}$.

Stereological cell counts. Counts of $\mathrm{TH}-$, NeuN-immunoreactive, and Nisslpositive neurons were performed on $20 \mu \mathrm{m}$-thick coronal microtome sections spaced $40 \mu \mathrm{m}$ apart throughout the extent of the AN, SN, VTA and LC. We followed procedures similar to those previously used in our laboratory ${ }^{43}$. Striatal $\mathrm{TH}+$ fiber density was quantified in a $20 \mu \mathrm{m}$-thick slice at Bregma $0.86^{44}$. The striatum was divided into dorsal and ventral areas and 10-20 random 3,565.2 $\mu \mathrm{m}^{2}$ dissectors per hemisphere were counted using the C.A.S.T. Grid System. $\mathrm{CB} \mathrm{TH}+$ cell counting was performed across the entire CB parenchyma. SCG $\mathrm{TH}+$ neurons were counted on $30 \mu \mathrm{m}$-thick coronal sections spaced $90 \mu \mathrm{m}$ apart throughout the extent of the structure. Random dissectors of $5,347.7 \mu \mathrm{m}^{2}$ were used.

Open field. We used N7 C57BL/6 animals in open field analysis. Behavioral assessment for motor dysfunction was performed in a box of $22.5 \times 22.5 \mathrm{~cm}^{2}$ floor and with 42-cm-high walls. Four boxes were monitored at the same time using an automatic tracking system (SMART, Panlab, Spain). Animals were recorded for $60 \mathrm{~min}$ and several horizontal motor parameters were calculated using the SMART software (v2.5.14). Vertical movements were estimated by visual inspection of the recorded videos using the specific tool provided by the software (SMART).

Statistical analysis. Data were presented as mean \pm s.e.m., and were analyzed with either Student's t test or one-way ANOVA followed by Tukey test. $p<0.05$ was considered statistically significant.

\section{ACKNOWLEDGMENTS}

We wish to thank Drs. Ricardo Pardal, Michael Patterson and Juan J. ToledoAral for comments on the manuscript and Javier Sanchez García for karyotyping of ES cells. Support was obtained from the Juan March Foundation, the Marcelino Botín Foundation, the Spanish Ministry of Science 
and Education, the Spanish Ministry of Health (TERCEL), and the Andalusian Government. CIBERNED is funded by the "Instituto de Salud Carlos III".

\section{AUTHOR CONTRIBUTIONS}

A. P. and M. H.-F. designed and conducted most of the experiments. A.P., C.O.P., R.G. and J.I.P. generated the GDNF conditional knockout animals. J.L.B. supervised the project. A.P. and J.L.-B. wrote the manuscript.

\section{REFERENCES}

1. Lin, L. F., Doherty, D. H., Lile, J. D., Bektesh, S. \& Collins, F. GDNF: a glial cell line-derived neurotrophic factor for midbrain dopaminergic neurons. Science 260, 1130-1132 (1993).

2. Kirik, D., Georgievska, B. \& Bjorklund, A. Localized striatal delivery of GDNF as a treatment for Parkinson disease. Nat. Neurosci. 7, 105-110 (2004).

3. Akerud, P., Canals, J. M., Snyder, E. Y. \& Arenas, E. Neuroprotection through delivery of glial cell line-derived neurotrophic factor by neural stem cells in a mouse model of Parkinson's disease. J. Neurosci. 21, 8108-8118 (2001).

4. Choi-Lundberg, D. L. et al. Dopaminergic neurons protected from degeneration by GDNF gene therapy. Science 275, 838-841 (1997).

5. Gash, D. M. et al. Functional recovery in parkinsonian monkeys treated with GDNF. Nature 380, 252-255 (1996).

6. Kordower, J. H. et al. Neurodegeneration prevented by lentiviral vector delivery of GDNF in primate models of Parkinson's disease. Science 290, 767-773 (2000).

7. Rosenblad, C., Martinez-Serrano, A. \& Bjorklund, A. Intrastriatal glial cell line-derived neurotrophic factor promotes sprouting of spared nigrostriatal dopaminergic afferents and induces recovery of function in a rat model of Parkinson's disease. Neuroscience 82, 129-137 (1998).

8. Tomac, A. et al. Protection and repair of the nigrostriatal dopaminergic system by GDNF in vivo. Nature 373, 335-339 (1995).

9. Arenas, E., Trupp, M., Akerud, P. \& Ibanez, C. F. GDNF prevents degeneration and promotes the phenotype of brain noradrenergic neurons in vivo. Neuron 15, 1465-1473 (1995).

10. Gill, S. S. et al. Direct brain infusion of glial cell line-derived neurotrophic factor in Parkinson disease. Nat. Med. 9, 589-595 (2003).

11. Slevin, J. T. et al. Improvement of bilateral motor functions in patients with Parkinson disease through the unilateral intraputaminal infusion of glial cell line-derived neurotrophic factor. J. Neurosurg. 102, 216-222 (2005).

12. Lang, A. E. et al. Randomized controlled trial of intraputamenal glial cell line-derived neurotrophic factor infusion in Parkinson disease. Ann. Neurol. 59, 459-466 (2006). 
13. Check, E. Second chance. Nat. Med. 13, 770-771 (2007).

14. Trupp, M., Belluardo, N., Funakoshi, H. \& Ibanez, C. F. Complementary and overlapping expression of glial cell line-derived neurotrophic factor (GDNF), c-ret proto-oncogene, and GDNF receptor-alpha indicates multiple mechanisms of trophic actions in the adult rat CNS. J. Neurosci. 17, 3554-3567 (1997).

15. Toledo-Aral, J. J., Mendez-Ferrer, S., Pardal, R., Echevarria, M. \& Lopez-Barneo, J. Trophic restoration of the nigrostriatal dopaminergic pathway in long-term carotid body-grafted parkinsonian rats. J. Neurosci. 23, 141-148. (2003).

16. Villadiego, J. et al. Selective glial cell line-derived neurotrophic factor production in adult dopaminergic carotid body cells in situ and after intrastriatal transplantation. J. Neurosci. 25, 4091-4098 (2005).

17. Arjona, V. et al. Autotransplantation of human carotid body cell aggregates for treatment of Parkinson's disease. Neurosurgery 53, 321328; discussion 328-330 (2003).

18. Espejo, E. F., Montoro, R. J., Armengol, J. A. \& Lopez-Barneo, J. Cellular and functional recovery of Parkinsonian rats after intrastriatal transplantation of carotid body cell aggregates. Neuron 20, 197-206. (1998).

19. Minguez-Castellanos, A. et al. Carotid body autotransplantation in Parkinson disease: A clinical and PET study. J. Neurol. Neurosurg. Psychiatry 78, 825-831 (2007).

20. Moore, M. W. et al. Renal and neuronal abnormalities in mice lacking GDNF. Nature 382, 76-79 (1996).

21. Pichel, J. G. et al. Defects in enteric innervation and kidney development in mice lacking GDNF. Nature 382, 73-76 (1996).

22. Sanchez, M. P. et al. Renal agenesis and the absence of enteric neurons in mice lacking GDNF. Nature 382, 70-73 (1996).

23. Boger, H. A. et al. A partial GDNF depletion leads to earlier age-related deterioration of motor function and tyrosine hydroxylase expression in the substantia nigra. Exp. Neurol. 202, 336-347 (2006).

24. Boger, H. A. et al. Long-term consequences of methamphetamine exposure in young adults are exacerbated in glial cell line-derived neurotrophic factor heterozygous mice. J. Neurosci. 27, 8816-8825 (2007).

25. Jain, $S$. et al. RET is dispensable for maintenance of midbrain dopaminergic neurons in adult mice. J. Neurosci. 26, 11230-11238 (2006).

26. Kramer, E. R. et al. Absence of Ret signaling in mice causes progressive and late degeneration of the nigrostriatal system. PLoS Biol. 5, e39 (2007).

27. Hayashi, S. \& McMahon, A. P. Efficient recombination in diverse tissues by a tamoxifen-inducible form of Cre: a tool for temporally regulated gene activation/inactivation in the mouse. Dev. Biol. 244, 305-318 (2002).

28. Bjorklund, A. \& Hokfelt, T. Handbook of Chemical Neuroanatomy: Classical Neurotransmitters in fhe CNS, Part I, 123-156. Elsevier, Amsterdam (1984). 
29. Lindvall, O. \& Stenevi, U. Dopamine and noradrenaline neurons projecting to the septal area in the rat. Cell Tissue Res. 190, 383-407 (1978).

30. Galarza, M. Evidence of the subcommissural organ in humans and its association with hydrocephalus. Neurosurg. Rev. 25, 205-215 (2002).

31. Fleming, S. M. et al. Early and progressive sensorimotor anomalies in mice overexpressing wild-type human alpha-synuclein. J. Neurosci. 24, 9434-9440 (2004).

32. Meredith, G. E. \& Kang, U. J. Behavioral models of Parkinson's disease in rodents: a new look at an old problem. Mov. Disord. 21, 1595-1606 (2006).

33. Sedelis, M., Schwarting, R. K. \& Huston, J. P. Behavioral phenotyping of the MPTP mouse model of Parkinson's disease. Behav. Brain Res. 125, 109-125 (2001).

34. Zhou, Q. Y. \& Palmiter, R. D. Dopamine-deficient mice are severely hypoactive, adipsic, and aphagic. Cell 83, 1197-1209 (1995).

35. Granholm, A. C. et al. Glial cell line-derived neurotrophic factor is essential for postnatal survival of midbrain dopamine neurons. J. Neurosci. 20, 3182-3190 (2000).

36. Paratcha, G., Ledda, F. \& Ibanez, C. F. The neural cell adhesion molecule NCAM is an alternative signaling receptor for GDNF family ligands. Cell 113, 867-879 (2003).

37. Chao, C. C., Ma, Y. L., Chu, K. Y. \& Lee, E. H. Integrin alphav and NCAM mediate the effects of GDNF on DA neuron survival, outgrowth, DA turnover and motor activity in rats. Neurobiol. Aging 24, 105-116 (2003).

38. Tome, M. et al. The subcommissural organ expresses D2, D3, D4, and D5 dopamine receptors. Cell Tissue Res. 317, 65-77 (2004).

39. Zarow, C., Lyness, S. A., Mortimer, J. A. \& Chui, H. C. Neuronal loss is greater in the locus coeruleus than nucleus basalis and substantia nigra in Alzheimer and Parkinson diseases. Arch. Neurol. 60, 337-341 (2003).

40. Matzuk, M. M. \& Saper, C. B. Preservation of hypothalamic dopaminergic neurons in Parkinson's disease. Ann. Neurol. 18, 552-555 (1985).

41. Srinivasan, J. \& Schmidt, W. J. Potentiation of parkinsonian symptoms by depletion of locus coeruleus noradrenaline in 6-hydroxydopamineinduced partial degeneration of substantia nigra in rats. Eur. J. Neurosci. 17, 2586-2592 (2003).

42. Guo, C., Yang, W. \& Lobe, C. G. A Cre recombinase transgene with mosaic, widespread tamoxifen-inducible action. Genesis 32, 8-18 (2002).

43. Mejias, R. et al. Neuroprotection by transgenic expression of glucose-6phosphate dehydrogenase in dopaminergic nigrostriatal neurons of mice. J, Neurosci, 26, 4500-4508 (2006).

44. Franklin, B. J., Paxinos, G. T. The Mouse Brain in Stereotaxic Coordinates. New York: Academic Press (1996). 


\section{FIGURE LEGENDS}

Figure 1 Molecular characterization of the conditional GDNF knockout mice. (a) GDNF wild-type locus, targeting construct, floxed and excised alleles are shown. B, BamHI. Probe and genotyping PCRs are indicated. Gray rectangles represent Neo marker and triangles loxP sequences. (b) ES cell clone showing correct targeting at the GDNF locus by Southern blotting. BamHI-digested DNA was hybridized with the probe indicated in (a). An additional band is present in GDNF $F^{+/ F}$ ES cells (+/F). (c) Floxed PCR used for genotyping of GNDF $^{+/+}(+/+)$, $G D N F^{+/ F}(+/ F)$, and $G D N F^{F / F}(F / F)$ mice are shown. The ES GDNF ${ }^{+/ F}$ cell line is showed as a control (+/F). (d) Experimental protocol used for analysis of TMXtreated animals. Time points of TMX injection and brain harvesting for DNA, protein $(\mathrm{P})$, RNA, and histological analyses $(\mathrm{H})$ are indicated (m, months). (e) PCR used to demonstrate the presence of the excised GDNF allele in the striatum after TMX treatment. GDNF ${ }^{F /-}$; Cre-Esr1 animals without $(-T M X)$ and with (+TMX) TMX treatment are shown. (f) Relative levels of GDNF mRNA determined by qRT-PCR. (+/+: GDNF ${ }^{F /+}$; +. +/-: GDNF ${ }^{+/-}$; Cre-Esr1. F/-: GDNF ${ }^{F /-}$; Cre-Esr1). (g) Levels of striatal GDNF protein determined by ELISA. (+/+: GDNF $F^{F /+} ;$ +. F/-: GDNF ${ }^{F /-}$; Cre-Esr1). (h) Relative levels of tyrosine hydroxylase $(T H)$, choline acetyltransferase (CHAT), and glutamic acid decarboxylase (GAD1) mRNA in whole brain extracts determined by qRT-PCR. GDNF $F^{F /-}$, Cre-Esr1 mice without (black bars) and with (gray bars) TMX treatment. Means \pm s.e.m.; ${ }^{*}, p<0.05 ;{ }^{\star *}, p<0.01$ (Student $t$-test). $n=3-6$ samples per group.

Figure 2 Mesencephalic dopaminergic neuronal death after GDNF ablation in adult mouse. $(\mathbf{a}, \mathbf{b})$ Mesencephalic brain slices stained with an antibody against TH. SN, substantia nigra; VTA, ventral tegmental area. GDNF ${ }^{F /-}$, Cre-Esr1 mice without (a) and with (b) TMX treatment. (c,d) Unbiased stereological cell counts of SN (c) and VTA (d) TH immunoreactive neurons at 30 days (30 d) and 210 days $(210 \mathrm{~d})$ after TMX treatment. $G D N F^{+/+}$treated with TMX (black bars), GDNF ${ }^{F /-}$, Cre-Esr1 mice without (dark gray bars) and with (light gray bars) TMX treatment. (e,f) Double immunostaining of mesencephalic brain slices with antibodies against NeuN (nuclear) and $\mathrm{TH}$ (cytoplasmic). The stippled lines 
surround the SN and VTA. Inset in (e) represents a magnification of the indicated zone. GDNF ${ }^{\mathrm{F} /}$, Cre-Esr1 mice without (e) and with (f) TMX treatment. $(\mathbf{g}, \mathbf{h})$ Unbiased stereological cell counts of SN (c) and VTA (d) NeuN immunoreactive neurons after 210 days of TMX treatment. GDNF ${ }^{F /}$, Cre-Esr1 mice without and GDNF ${ }^{+/+}$with TMX treatment (black bars), and GDNF ${ }^{F /-}$, CreEsr1 mice with TMX treatment (light gray bars). Means \pm s.e.m.; *, $p<0.05$; **, $p<0.01$ (Student $t$-test). $n=6-8$ samples per group. Scale bars, $100 \mu \mathrm{m}$.

Figure 3. Locus coeruleus noradrenergic neuronal death after GDNF ablation in adult mouse. $(\mathbf{a}, \mathbf{b})$ Hindbrain slices stained with an antibody against $\mathrm{TH}$. At the bottom panels, the respective right locus coeruleus (LC) are shown at higher magnification. (c,d) Nissl stainning of brain slices containing LC. GDNF ${ }^{\mathrm{F} /}$, CreEsr1 mice without $(\mathbf{a}, \mathbf{c})$ and with $(\mathbf{b}, \mathbf{d}) \mathrm{TMX}$ treatment. The stippled lines highlight the LC. (e) Unbiased stereological cell counts of LC TH immunoreactive neurons at 30 days (30 d) and 210 days (210 d) after TMX treatment. GDNF ${ }^{+/+}$treated with TMX (black bars), GDNF ${ }^{F /-}$, Cre-Esr1 mice without (dark gray bars) and with (light gray bars) TMX treatment. (f) Unbiased stereological cell counts of LC Nissl positive neurons after 210 days of TMX treatment. GDNF ${ }^{F /}$, Cre-Esr1 mice without and $G D N F^{+/+}$with $\mathrm{TMX}$ treatment (black bars), and GDNF ${ }^{F /}$, Cre-Esr1 mice with TMX treatment (gray bars). Means \pm s.e.m.; *, $p<0.05 ;{ }^{\star *}, p<0.01$ (Student $t$-test). $n=5-8$ samples per group. Scale bars are $100 \mu \mathrm{m}$ in all panels except panels e,f (top) where they represent $500 \mu \mathrm{m}$.

Figure 4 Peripheral and hypothalamic dopaminergic cell survival in conditional GDNF knockout mice. $(\mathbf{a}, \mathbf{b})$ Carotid body (CB) of $G D N F^{F /-}$, Cre-Esr1 mice without (a) and with (b) TMX treatment as revealed by TH immunoreactivity. (ce) $\mathrm{TH}+$ cells of the arcuate nucleus (AN). (c) Brain section immunostained for $\mathrm{TH}$ indicating the location of the arcuate nucleus (AN). The encircled zone represents the area shown in $\mathbf{d}$ and $\mathbf{e}$. $(\mathbf{d}, \mathbf{e}) \mathrm{TH}+$ cells of $A N$ from $G D N F^{F /}$, CreEsr1 mice without (d) and with (e) TMX treatment. Scale bars are100 $\mu \mathrm{m}$ in all panels except panel c where it represents $500 \mu \mathrm{m}$. 
Figure 5. Behavioral analysis of adult GDNF-depleted mice. Spontaneous activity was measured in wild-type (black bars: $G D N F^{+/+}$; + mice treated with TMX; $n=13$ ) and GDNF depleted animals (gray bars: $G D N F^{F /}$; Cre-Esr1 mice treated with TMX; $n=7$ ) 3 days before TMX injection and 37, 60, 100, and 126 days after TMX injection. Animals were recorded during $60 \mathrm{~min}$ in an open field chamber. (a) Four traces from wild-type and GDNF-depleted animals are shown as representative of the time points 100 and 126 days after TMX injection. Activity trace during minutes 16 to 30 is presented. (b) Traveled distance $(\mathrm{cm})$ was calculated by following the centre of gravity of the subject. (c) Resting time (s) was the time spent in resting state (with reference to the default velocity threshold of $2.57 \mathrm{~cm} / \mathrm{s}$ ). (d,e) Vertical movements quantified in three periods of five minutes from each animal and time point. Averaged number of rearings $(\mathrm{N}$, d) and the accumulated time spent with both forepaws without contacting the floor (e) are shown. Each individual point represents 3-8 animals. Means \pm s.e.m.; *, $p<0.05 ;{ }^{*}, p<0.01$ (Tukey test). 


\begin{tabular}{|c|c|c|c|c|}
\hline & & $\mathrm{GDNF}^{\mathrm{F} /+}(\mathrm{TMX}+)$ & GDNF $F^{F /-}$, Cre (TMX-) & $\mathrm{GDNF}^{\mathrm{F} /-}$, Cre $(\mathrm{TMX}+)$ \\
\hline \multirow[t]{3}{*}{ SN } & $\begin{array}{l}\mathrm{TH}+ \\
(30 \mathrm{~d})\end{array}$ & $\begin{array}{c}4,252 \pm 336^{\$} \\
(n=8)\end{array}$ & & $\begin{array}{c}3,440 \pm 209 \\
(n=6)\end{array}$ \\
\hline & $\begin{array}{c}\text { TH+ } \\
(210 \mathrm{~d})\end{array}$ & $\begin{array}{c}4,787 \pm 480 \\
(n=8)\end{array}$ & $\begin{array}{c}4,931 \pm 865 \\
(n=6)\end{array}$ & $\begin{array}{c}2,029 \pm 469 * * * * \\
(n=6)\end{array}$ \\
\hline & $\begin{array}{l}\text { NeuN+ } \\
(210 \mathrm{~d})\end{array}$ & $\begin{array}{c}11,289 \pm 510^{\$} \\
(n=6)\end{array}$ & & $\begin{array}{c}8,356 \pm 720 * * \\
(n=6)\end{array}$ \\
\hline \multirow[t]{3}{*}{ VTA } & $\begin{array}{l}\mathrm{TH}+ \\
(30 \mathrm{~d})\end{array}$ & $\begin{array}{c}2,763 \pm 193^{\$} \\
(n=8)\end{array}$ & & $\begin{array}{c}2,481 \pm 150 \\
(n=6)\end{array}$ \\
\hline & $\begin{array}{c}\mathrm{TH}+ \\
(210 \mathrm{~d})\end{array}$ & $\begin{array}{c}2,561 \pm 427 \\
(n=6)\end{array}$ & $\begin{array}{c}2,919 \pm 238 \\
(n=6)\end{array}$ & $\begin{array}{c}872 \pm 381^{* / * *} \\
(n=6)\end{array}$ \\
\hline & $\begin{array}{l}\text { NeuN+ } \\
(210 \mathrm{~d})\end{array}$ & $\begin{array}{c}5,855 \pm 421^{\$} \\
(n=6)\end{array}$ & & $\begin{array}{c}2,156 \pm 586^{* *} \\
(n=6)\end{array}$ \\
\hline \multirow[t]{3}{*}{ LC } & $\begin{array}{l}\mathrm{TH}+ \\
(30 \mathrm{~d})\end{array}$ & $\begin{array}{c}892 \pm 138^{\$} \\
(n=7)\end{array}$ & & $\begin{array}{c}785 \pm 137 \\
(n=6)\end{array}$ \\
\hline & $\begin{array}{c}\text { TH+ } \\
(210 \mathrm{~d})\end{array}$ & $\begin{array}{c}873 \pm 131 \\
(n=5)\end{array}$ & $\begin{array}{c}850 \pm 301 \\
(n=5)\end{array}$ & $\begin{array}{c}5 \pm 3^{* * / * *} \\
(n=6)\end{array}$ \\
\hline & $\begin{array}{l}\text { Nissl+ } \\
(210 \mathrm{~d})\end{array}$ & $\begin{array}{c}2,489 \pm 363^{\$} \\
(n=7)\end{array}$ & & $\begin{array}{c}1,537 \pm 169 * \\
(n=6)\end{array}$ \\
\hline AN & $\begin{array}{c}\mathrm{TH}+ \\
(210 \mathrm{~d})\end{array}$ & $\begin{array}{c}264 \pm 99^{\$} \\
(n=8)\end{array}$ & & $\begin{array}{c}268 \pm 109 \\
(n=6)\end{array}$ \\
\hline dST & $\begin{array}{c}\text { TH+ } \\
(210 \mathrm{~d})\end{array}$ & $\begin{array}{l}21.4 \pm 1.6^{\$} \\
(n=12)\end{array}$ & & $\begin{array}{c}15.4 \pm 1.4^{*} \\
(n=6)\end{array}$ \\
\hline vST & $\begin{array}{c}\text { TH+ } \\
(210 \mathrm{~d})\end{array}$ & $\begin{array}{c}26.9 \pm 2.2^{\$} \\
(n=9)\end{array}$ & & $\begin{array}{c}17.1 \pm 1.7^{* *} \\
(n=6)\end{array}$ \\
\hline CB & $\begin{array}{c}\mathrm{TH}+ \\
(210 \mathrm{~d})\end{array}$ & $\begin{array}{c}1,102.1 \pm 67.2^{\$} \\
(n=3)\end{array}$ & & $\begin{array}{c}418.1 \pm 122.5^{\star *} \\
(n=3)\end{array}$ \\
\hline SCG & $\begin{array}{c}\mathrm{TH}+ \\
(210 \mathrm{~d})\end{array}$ & $\begin{array}{c}10,036 \pm 1,105^{\$} \\
(n=3)\end{array}$ & & $\begin{array}{c}4,736 \pm 571^{* *} \\
(n=5)\end{array}$ \\
\hline \multicolumn{5}{|c|}{ 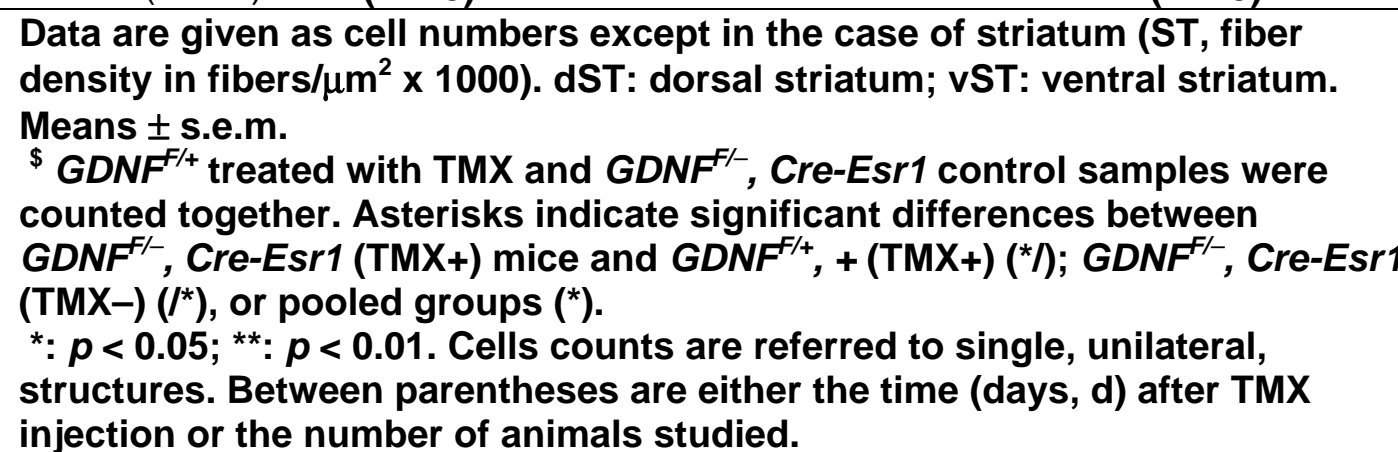 } \\
\hline
\end{tabular}


SI Guide

Journal: Nature Neuroscience

\begin{tabular}{|l|c|}
\hline Article Title: & $\begin{array}{c}\text { Absolute Requirement of GDNF for Adult } \\
\text { Catecholaminergic Neuron Survival }\end{array}$ \\
\hline $\begin{array}{l}\text { Corresponding } \\
\text { Author: }\end{array}$ & José López-Barneo \\
\hline & \\
\hline
\end{tabular}

\begin{tabular}{|l|l|}
\hline $\begin{array}{l}\text { Supplementary Item } \\
\text { \& Number } \\
\text { (add rows as necessary) }\end{array}$ & Title or Caption \\
\hline Supplementary Figure 1 & Cortex and hippocampus in GDNF-depleted mice \\
\hline Supplementary Figure 2 & GDNF expression in catecholaminergic brain targets \\
\hline Supplementary Methods & Primers used for quantitative RT-PCR \\
\hline
\end{tabular}


a
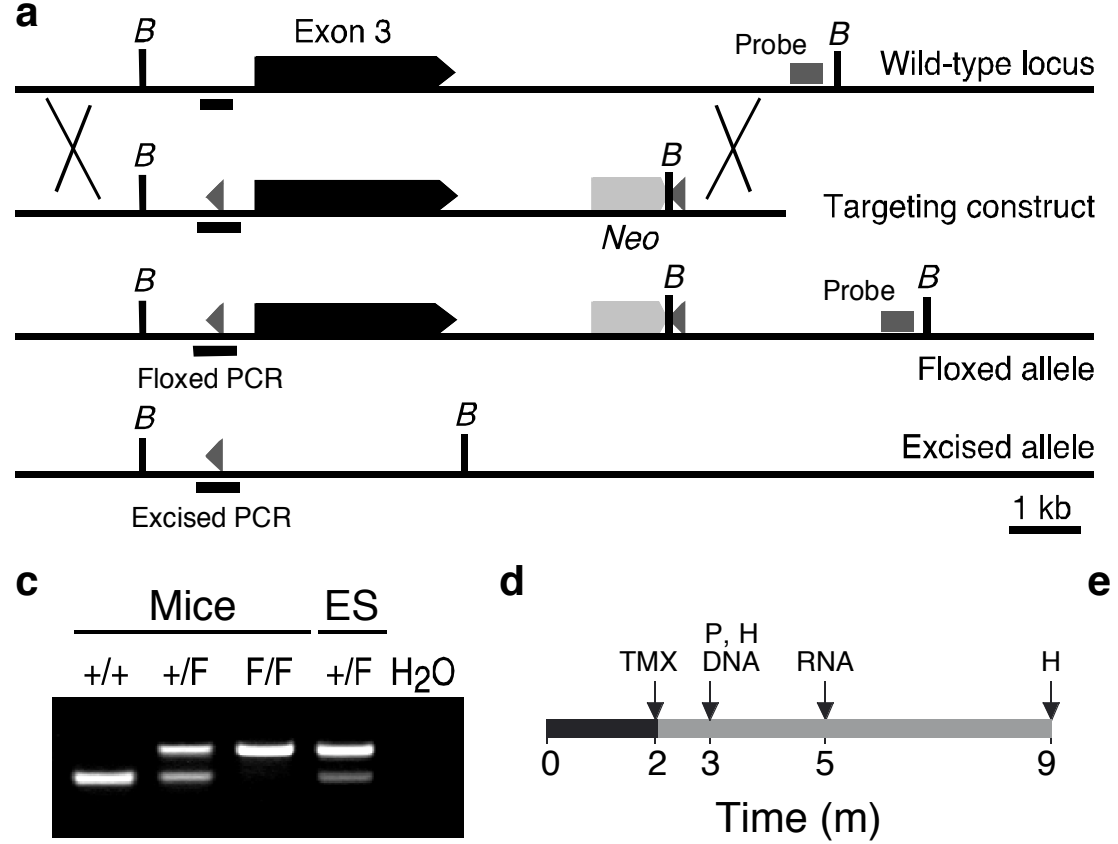

f

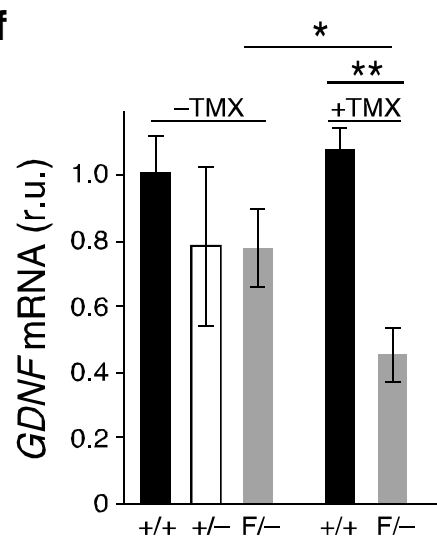

b
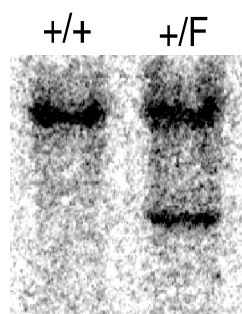

Excised allele

$1 \mathrm{~kb}$

d

e

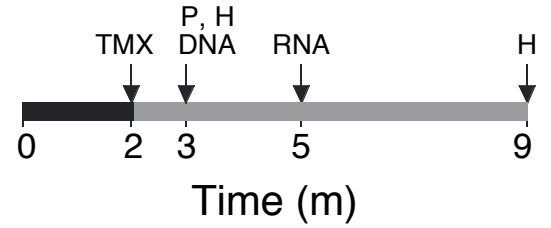

Cre-Esr1

$\mathrm{H}_{2} \mathrm{O}-\mathrm{TMX}+\mathrm{TMX}$

g

h

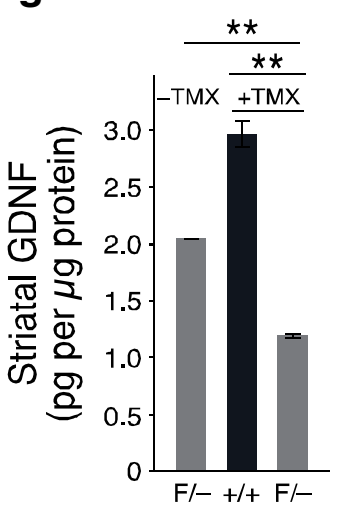

Figure 1

Pascual et al. 

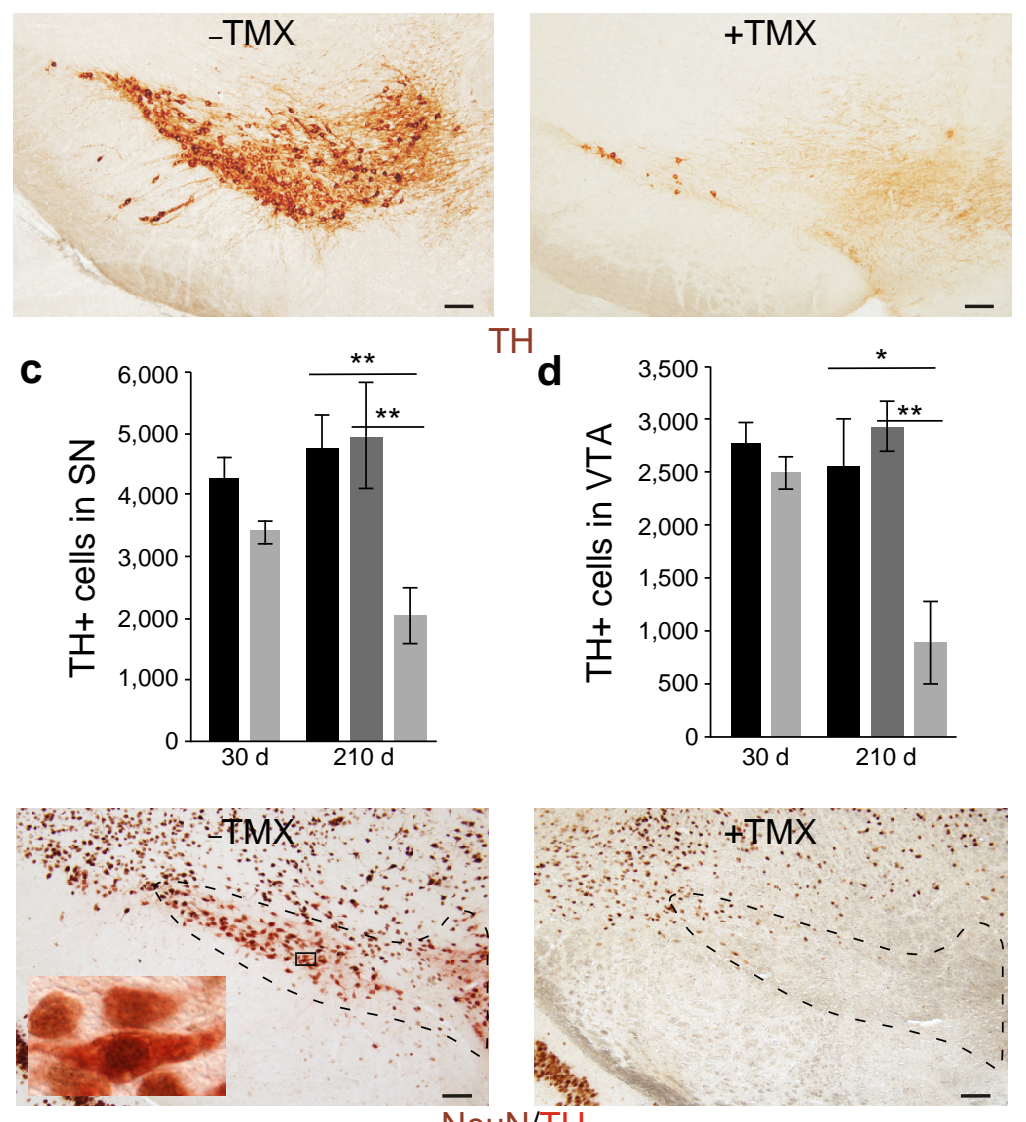

g

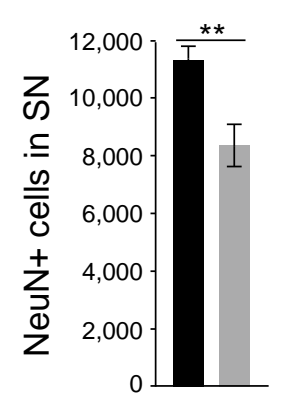

h

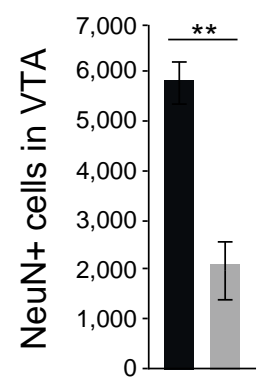

Figure 2

Pascual et al. 

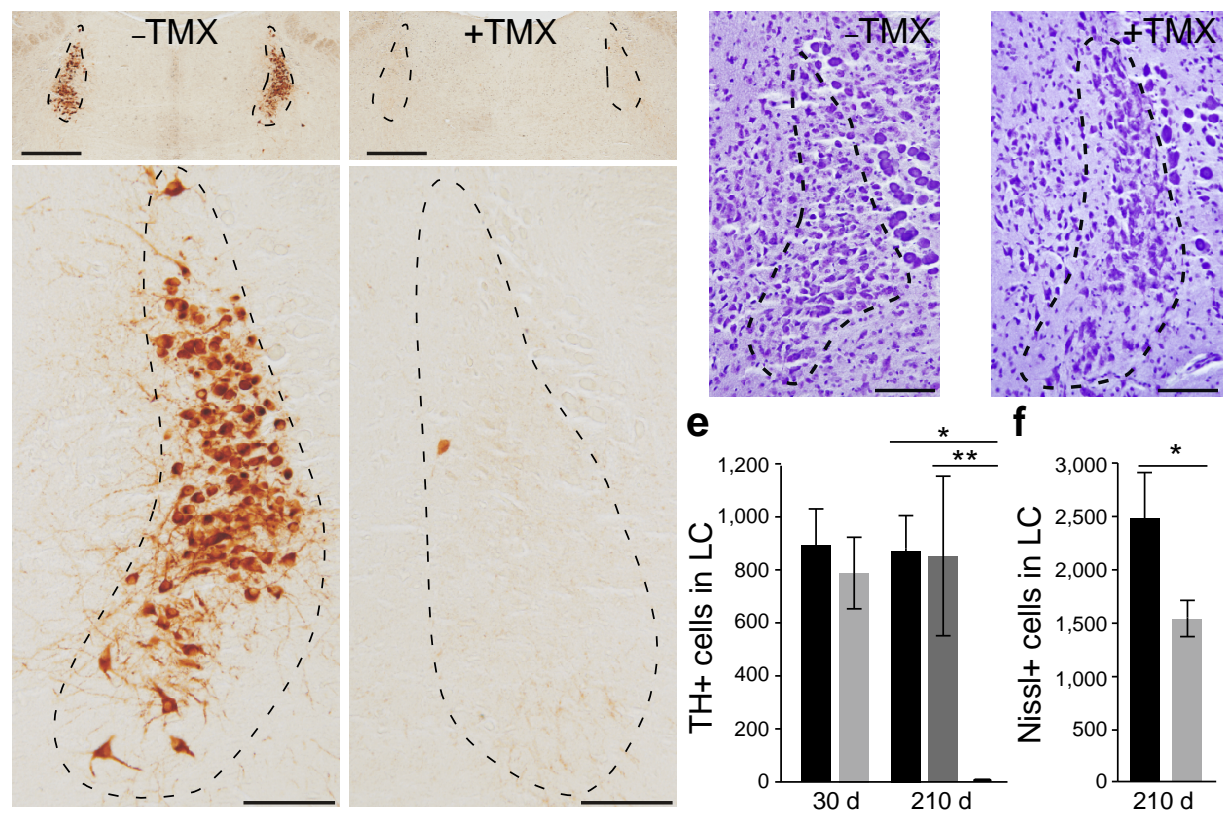

Figure 3

Pascual et al. 
CB

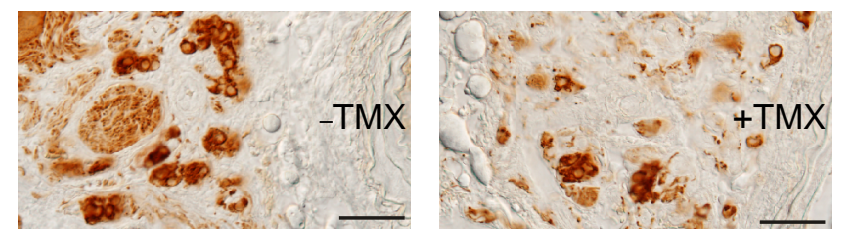

AN

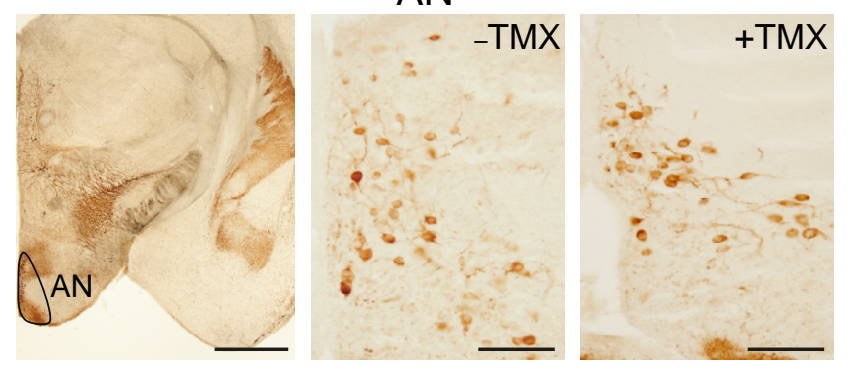

Figure 4

Pascual et al. 
a

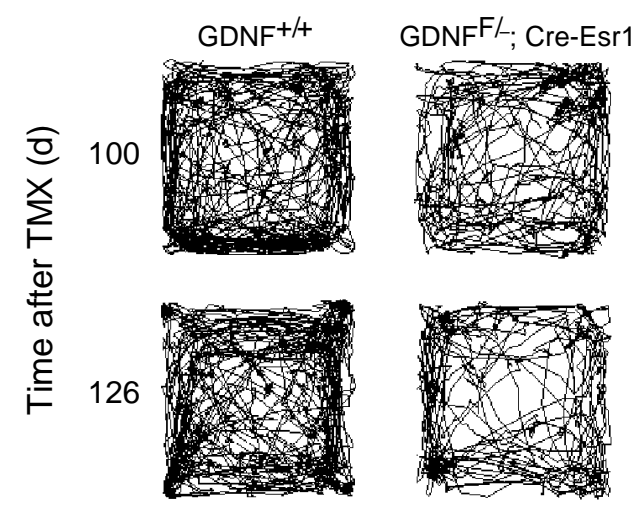

b

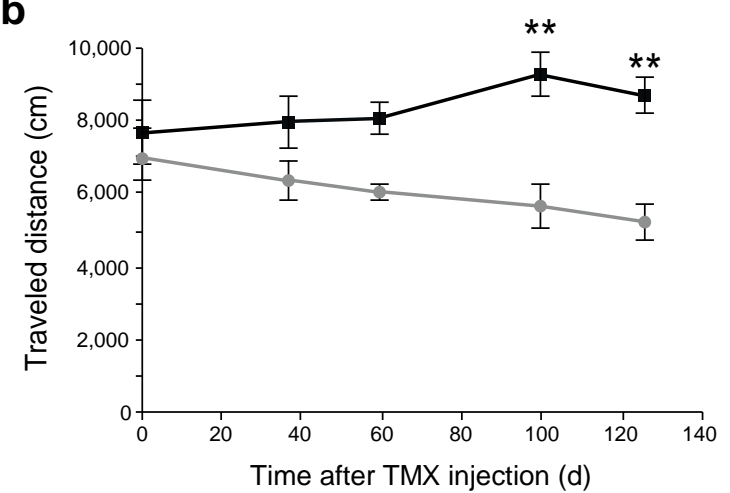

C

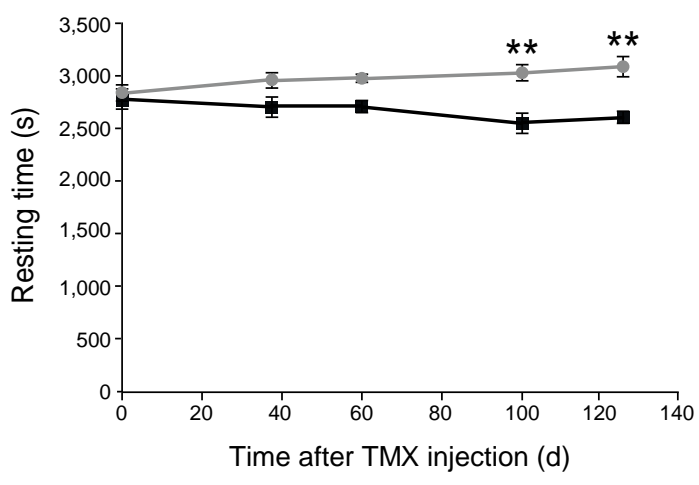

- $\mathrm{GDNF}^{+/+}$

GDNFF/-; Cre-Esr1

d

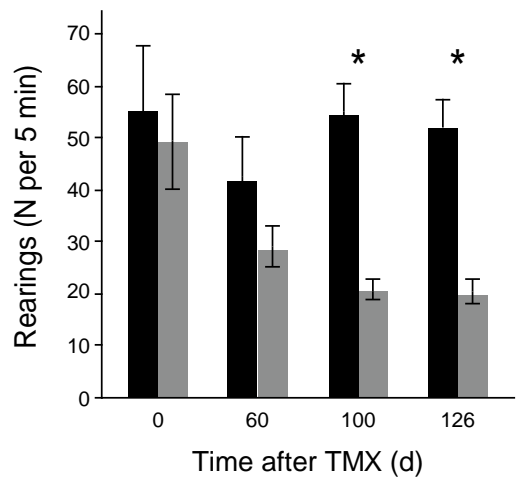

e

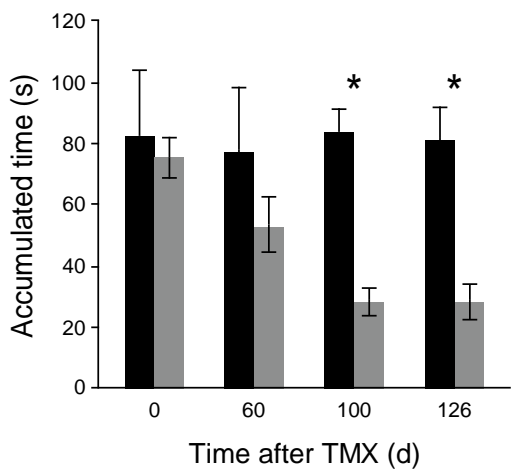

Figure 5

Pascual et al. 


\section{SUPPLEMENTARY INFORMATION}

\section{Absolute Requirement of GDNF for Adult Catecholaminergic Neuron Survival}

Alberto Pascual, María Hidalgo-Figueroa, José I. Piruat, C. Oscar Pintado, Raquel Gómez-Díaz and José López-Barneo

Instituto de Biomedicina de Sevilla, Hospital Universitario Virgen del Rocío/ CSIC/Universidad de Sevilla. Sevilla, Spain. 


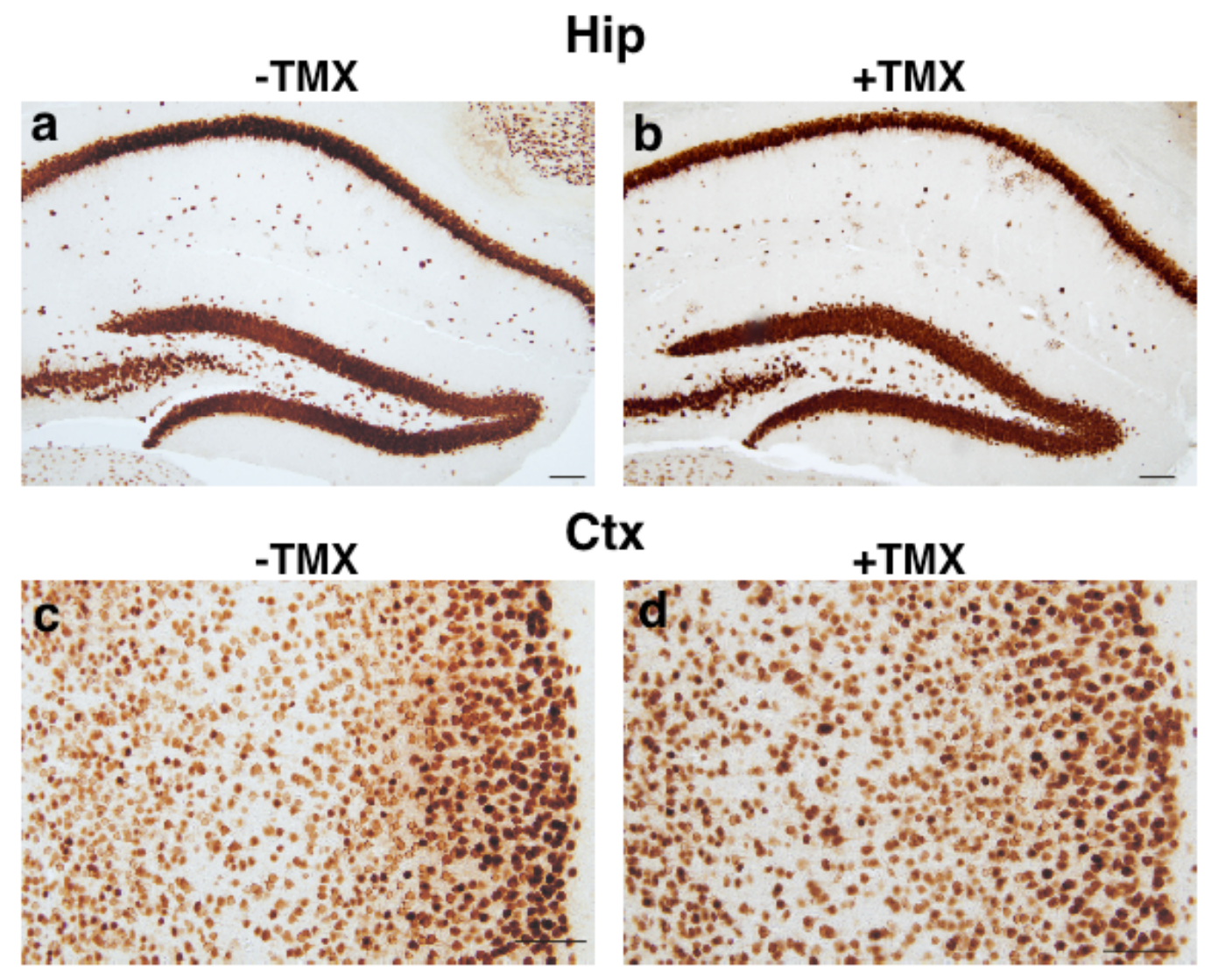

Supplementary Figure 1. Cortex and hippocampus in GDNF-depleted mice. (a-d) Brain slices from GDNF ${ }^{F /}$, Cre-Esr1 mice without $(\mathbf{a}, \mathbf{c})$ and with $(\mathbf{b}, \mathbf{d})$ TMX treatment stained with an antibody against NeuN. (a,b) hippocampus (Hip); (i,j) cortex (Ctx). Scale bar indicates $100 \mu \mathrm{m}$. 


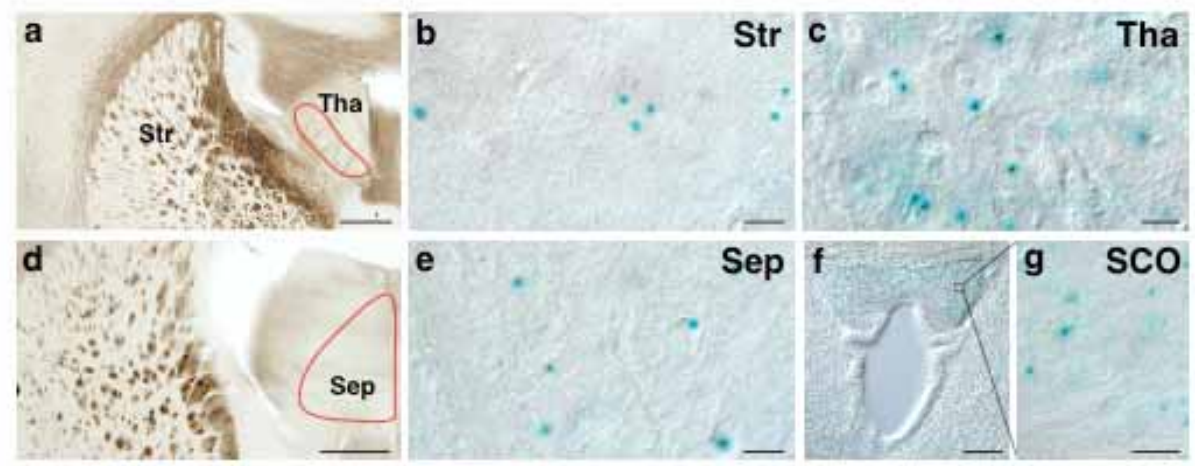

Supplementary Figure 2. GDNF expression in catecholaminergic brain targets. GDNF promoter activity as estimated by ß-galactosidase enzymatic detection in brains from heterozygous GDNF ${ }^{L a c Z}$ mice (Sanchez et al., 1996; Villadiego et al., 2005). (a-c) Coronal brain section demonstrating high GDNF expression in the striatum (b, Str) and thalamus (c, Tha). The region encircled by the red line (a) represents the area in thalamus with a high density of X-gal+ cells. (d-e) Coronal brain section demonstrating high GDNF expression in the septum (e, Sep). The region encircled by the red line (d) represents the septal area with a high density of X-gal+ cells (f-g) GDNF expression in the subcommissural organ (SCO). Scale bar indicates $500 \mu \mathrm{m}$ in a and d; $10 \mu \mathrm{m}$ in b, c, e and $\mathbf{g}$; and 50 $\mu \mathrm{m}$ in $\mathbf{f}$. 


\section{Supplementary Methods}

\section{Primers used for quantitative RT-PCR}

Primers were designed using Primer Express software (Applied-Biosystems).

The following primers were used:

B-actin (Actb), 5'-GGCCCAGAGCAAGAGAGGTA-3' and 5'CATGTCGTCCCAGTTGGTAACA-3';

cyclophilin A (Ppia), 5'-ATGGCAAATGCTGGACCAAA-3' and 5'TGCCATCCAGCCATTCAGT-3';

tyrosine hydroxylase (TH), 5'-GGCTTCTCTGACCAGGCGTAT-3' and 5'GCTCACCCTGCTTGTATTGGA-3';

choline acetyltransferase (Chat), 5'-GGAGCGAATCGTTGGTATGAC-3' and 5'ATCTCGGCCCACCACAAA-3';

glutamic acid decarboxylase (Gad1), 5'-ACTCCTCAACTATGTCCGCAAGA-3' and 5'-TCCAAATTAAAGCCTTCCATGC-3';

GDNF, 5'-GGATGGGATTCGGGCCACT-3' 5' AGCCACGACATCCCATAACTTC-3'.

B-glucuronidase (Gusb), 5'-CATTCAGTTCTGGATCAGAAACGTA-3' and 5'CATGAAGTCGGCGAAATTCC-3';

Neomycin (Neo), 5'- GGATGGAAGCCGGTCTTGT-3'and 5'CCTGATGCTCTTCGTCCAGATC-3'. 